\title{
Melanoma and occupation: results of a case-control study
}

\author{
Lin Fritschi, Jack Siemiatycki
}

\begin{abstract}
Objectives-Associations between occupational exposures and the occurrence of cutaneous melanoma were examined as part of a large population based case-control study of 19 cancer sites.

Methods-Cases were men aged 35 to 70 years old, resident in Montreal, Canada, with a new histologically confirmed cutaneous melanoma $(n=103)$. There were two control groups, a randomly selected population control group $(n=533)$, and a cancer control group $(n=533)$ randomly selected from among subjects with other types of cancer in the large study. Odds ratios for the occurrence of melanoma were calculated for each exposure circumstance for which there were more than four exposed cases (85 substances, 13 occupations, and 20 industries) adjusting for age, ethnicity, and number of years of schooling.
\end{abstract}

Results-Significantly increased risk of melanoma was found for exposure to four substances (fabric dust, plastic dust, trichloroethylene, and a group containing paints used on surfaces other than metal and varnishes used on surfaces other than wood), three occupations (warehouse clerks, salesmen, and miners and quarrymen), and two industries (clothing and non-metallic mineral products).

Conclusions-Most of the occupational circumstances examined were not associated with melanoma, nor is there any strong evidence from previous research that any of those are risk factors. For the few occupational circumstances which were associated in our data with melanoma, the statistical evidence was weak, and there is little or no supporting evidence in the scientific literature. On the whole, there is no persuasive evidence of occupational risk factors for melanoma, but the studies have been too small or have involved too much misclassification of exposure for this conclusion to be definitive.

(Occup Environ Med 1996;53:168-173)

Keywords: melanoma; occupational exposures; casecontrol

Exposure to the sun in susceptible people is accepted as the major cause of melanoma. ${ }^{1}$ Paradoxically, however, indoor workers seem to have a higher risk of melanoma than outdoor workers. ${ }^{23}$ There have been suggestions that this is due to different patterns of sun related behaviour in different occupational and social groups, but it is also possible that there are occupational exposures which are associated with melanoma in either a detrimental or, less probably, a protective way.

There have been some attempts to examine occupational exposures and melanoma, but most of these have had extremely few exposed cases, or have been retrospective cohort studies limited to one industry. Very few studies have had access to information on potential confounding factors such as complexion. Many of the population based studies have used deaths rather than incident cases, which is not appropriate for a cancer such as melanoma which has such a low case fatality rate.

A large population based study was undertaken in Montreal between 1979 and 1985 to examine possible associations between cancer and occupational exposures. ${ }^{4}$ Melanoma was one of the cancer sites included in the study. In a preliminary statistical analysis, estimates were made of the odds ratios (ORs) between each cancer site and each occupational exposure. Several substances, occupations, and industries were found to be associated with melanoma, ${ }^{4}$ however, this was a fairly crude analysis, with minimal control for potential confounders and little in the way of doseresponse analyses. In this paper, we examine the relation between occupational exposures to substances and melanoma in more detail, taking into account several potential confounding factors.

\section{Methods}

The subjects for this study were participants in a large case-control study of hundreds of occupational exposures and 19 cancer sites. This study has been described in detail elsewhere ${ }^{4}$ and a brief description only will be given here. Subjects were men aged 35 to 70 years, resident in Montreal, and with a new, histologically confirmed cancer. Between 1979 and 1985, there were 4576 eligible cancer patients, and 3730 of these $(82 \%)$ were successfully interviewed. Eighty one per cent of subjects responded for themselves, proxies provided information for the rest. There were 103 cases of cutaneous melanoma interviewed out of 124 eligible cases ( $83 \%$ response rate). A pool of potential controls (2525 subjects) was constituted from among all the other 
cancer patients, excluding lung cancer patients.

During the same period, 740 population controls were selected, in some years from electoral lists and in some years by random digit dialing. (In Canada, an actuve enumeration process results in virtually complete electoral lists, with addresses remaining current for about two years after an election.) Of these, $533(71 \%)$ were successfully interviewed and constituted the second control group.

A structured questionnaire was used to obtain information on several potential confounders. These included, age, ethnic origin, father's and mother's origin, birthplace, residence for the first 15 years of life, height and weight, years of schooling, annual income, and recent hobbies including gardening and outdoor sports. Present income was only available for $60 \%$ of subjects. For these subjects, a regression analysis was used to determine the relation between self reported income and mean income in the census tract of residence. This equation was then used to predict income for the subjects for whom income information was not available.

A semistructured probing interview was used to obtain detailed descriptions of all jobs the subject had had in his working life. A team of chemists and industrial hygienists examined each completed questionnaire and translated each job into a list of potential exposures to

Table 1 Percentage distribution of selected non-occupational variables among cases of melanoma, cancer controls, and population controls

\begin{tabular}{|c|c|c|c|c|}
\hline & $\begin{array}{l}\text { Cases of melanoma } \\
n=103\end{array}$ & $\begin{array}{l}\text { Cancer controls } \\
n=533\end{array}$ & $\begin{array}{l}\text { Population contrals } \\
n=533\end{array}$ & Pvalue \\
\hline Age (y): & & & & $<0.001$ \\
\hline 34 to 47 & 34 & 11 & 9 & \\
\hline 48 to 61 & 41 & 49 & 45 & \\
\hline 62 to 75 & 25 & 40 & 46 & \\
\hline \multicolumn{4}{|l|}{ Annual income (\$): } & $<0.001$ \\
\hline$<29890$ & 50 & 74 & 71 & \\
\hline$\geqslant 29890$ & 50 & 26 & 29 & \\
\hline \multicolumn{4}{|l|}{ Years of schooling: } & $<0.001$ \\
\hline $0-11$ & 44 & 73 & 68 & \\
\hline $12+$ & 56 & 27 & 32 & \\
\hline \multicolumn{4}{|l|}{ Ethnicity: } & $<0.001$ \\
\hline French & 38 & 60 & 64 & \\
\hline English speaking & 38 & 14 & 14 & \\
\hline Italian & 7 & 8 & 7 & \\
\hline Jewish & 9 & 5 & 3 & \\
\hline Other European & 7 & 8 & 8 & \\
\hline Other & 2 & 5 & 4 & \\
\hline \multicolumn{4}{|l|}{ Father's origin: } & 0.06 \\
\hline Canada & 62 & 64 & 70 & \\
\hline USA & 2 & 1 & 2 & \\
\hline$S$ Europe & 8 & 13 & 12 & \\
\hline N Europe & 25 & 18 & 12 & \\
\hline Asia or Africa & 2 & 3 & 3 & \\
\hline Other & 1 & 1 & 1 & \\
\hline \multicolumn{4}{|l|}{ Mother's origin: } & 0.03 \\
\hline Canada & 65 & 65 & 72 & \\
\hline USA & 3 & 2 & $<1$ & \\
\hline$S$ Europe & 7 & 12 & 11 & \\
\hline N Europe & 22 & 16 & 12 & \\
\hline Asia or Africa & 1 & 3 & 3 & \\
\hline Other & 2 & 1 & 1 & \\
\hline \multicolumn{4}{|l|}{ Birthplace: } & 0.01 \\
\hline Canada & 75 & 74 & 80 & \\
\hline USA & 2 & 1 & $<1$ & \\
\hline S Europe & 8 & 9 & 9 & \\
\hline N Europe & 11 & 11 & 6 & \\
\hline Asia or Africa & 2 & 3 & 3 & \\
\hline & 2 & 2 & 1 & \\
\hline \multicolumn{4}{|l|}{ Respondent: } & $<0.001$ \\
\hline self & 88 & 78 & 87 & \\
\hline proxy & 12 & 22 & 13 & \\
\hline \multicolumn{5}{|l|}{ Hobbies: } \\
\hline Gardening & 31 & 23 & 28 & 0.1 \\
\hline Outdoor sports & 52 & 37 & 46 & $<0.001$ \\
\hline
\end{tabular}

$\star^{2} \chi^{2}$ test for difference among the three groups with a univariate contingency table. substances by means of a checklist form which included 294 substances. For each substance, the chemists noted their degree of confidence that the exposure had actually occurred (possible, probable, definite), the frequency of exposure during a normal working week $(<5 \%$, $5 \%-30 \%$, or $>30 \%$ ), and the concentration of the substance in the environment. These three dimensions were combined as previously described $^{6}$ to produce three groups: unexposed, insubstantial exposure, and substantial exposure. The few subjects classified as only possibly exposed to a substance were excluded from analysis. Each job was also categorised as to specific occupation and industry by the chemists.

There were 469 possible exposure circumstances in our study: 294 substances, 98 occupations, and 77 industries. For the present analysis, only exposures with more than four cases of melanoma were examined: 85 substances, 13 occupations, and 20 industries.

Separate analyses were carried out with the cancer controls and the population controls. After confirming that the risk estimates were very similar with these two sets of controls, we decided to constitute a pooled group of population and cancer controls. So as to weight these two groups equally, we selected a random sample of 533 subjects from among the set of cancer controls. These included the following sites (number of cases in parentheses): colorectum (103), bladder (103), prostate (93), lymphoproliferative system (60), stomach (50), kidney (44), pancreas (26), and oesophagus (26). Unconditional logistic regression was used to model the risk of developing melanoma with each of the 118 occupational circumstances. Each regression model included the occupational circumstance of interest as well as the following covariates: age (continuous), number of years of schooling (continuous), and ethnicity (French, English speaking, or other). We explored alternative analytical procedures such as conditional logistic regression stratifying by age, ethnicity, and schooling, and Mantel-Haenszel estimates; the results were essentially the same as for the unconditional logistic regression model and will not be reported.

\section{Results}

Table 1 shows the distribution of the nonoccupational variables in the case and control groups. On average, cases of melanoma were younger than both groups of controls, had higher incomes, and more years of education. They were much less likely to be of French ancestry than controls. The distribution of parental origin differed slightly between groups but the distribution of birthplace was similar between groups. The patients with melanoma reported more outdoor sports, but this reflected their younger age; gardening was slightly more often reported by cases than controls.

There were high correlations between several of the non-occupational variables. In particular, years of schooling and present income 
were closely correlated, as were ethnicity, father's and mother's origin, and birthplace. Very few subjects had lived for the first 15 years of life in regions other than Canada or northern Europe, and those who had were primarily in the "other" group for ethnicity. We explored the inclusion of various subsets of the variables in table 1 in a logistic regression model with melanoma as the outcome. After including the three core variables age, number of years of schooling, and ethnicity, no additional improvement on the model was provided by including any of the other variables: income, parental origin, birthplace, country of residence as a child, gardening or outdoor sports as hobbies, or whether a proxy respondent was interviewed.

For most of the industries, occupations, and substances examined in this study the ORs for developing melanoma were not significantly different from 1.0 after controlling for age, ethnicity, and years of schooling. The appendix lists all of the occupational circumstances which were analysed and which did not satisfy the minimum criterion we established for earmarking potential associations; namely, a lower $95 \%$ confidence interval (95\% CI) greater than $0 \cdot 9$. One that is noteworthy in this list is the occupation of electric power worker, which had an OR of $2 \cdot 1(95 \%$ CI $0 \cdot 6-7 \cdot 5)$ based on five exposed cases. A significantly

Table 2 Industries and occupations with significant associations with melanoma in at least one multivariate analysis (lower 95\% CI > 90)

\begin{tabular}{lccc}
\hline Exposure & $\begin{array}{l}\text { Years } \\
\text { exposed }\end{array}$ & $\begin{array}{l}\text { Cases } \\
n\end{array}$ & $O R^{\star}(95 \%$ CI) \\
\hline Industry: & $1-9$ & 2 & $1 \cdot 4(0 \cdot 2-8 \cdot 3)$ \\
Clothing & $10+$ & 8 & $4 \cdot 1(1 \cdot 7-9 \cdot 8)$ \\
Non-metallic mineral products & $1-9$ & 2 & $1 \cdot 1(0 \cdot 3-5 \cdot 3)$ \\
Electrical and electronic products & $10+$ & 4 & $4 \cdot 6(1 \cdot 4-15 \cdot 5)$ \\
& $1-9$ & 4 & $0 \cdot 8(0 \cdot 2-2 \cdot 5)$ \\
Occupations: & $10+$ & 7 & $2 \cdot 4(1 \cdot 0-5 \cdot 9)$ \\
Warehouse clerks & $1-9$ & 7 & $1 \cdot 9(0 \cdot 8-4 \cdot 7)$ \\
Salesmen & $10+$ & 8 & $3 \cdot 4(1 \cdot 5-8 \cdot 1)$ \\
& $1-9$ & 9 & $1 \cdot 4(0 \cdot 7-3 \cdot 1)$ \\
Miners and quarrymen & $10+$ & 25 & $2 \cdot 5(1 \cdot 5-4 \cdot 3)$ \\
& $1-9$ & 4 & $3 \cdot 2(1 \cdot 0-10 \cdot 5)$ \\
Chemical processing workers & $10+$ & 1 & $6 \cdot 9(0 \cdot 7-65 \cdot 9)$ \\
& $1-9$ & 4 & $3 \cdot 4(1 \cdot 0-11 \cdot 1)$ \\
& $10+$ & 1 & $1 \cdot 7(0 \cdot 2-14 \cdot 8)$ \\
\hline
\end{tabular}

*Based on logistic regression including age, years of schooling, and ethnic group. Control group consisted of 1066 subjects, pooled from cancer controls and population controls.

Table 3 Exposures to substances with significant associations with melanoma in at least one multivariate analysis (lower $95 \% C I>0.9$ )

\begin{tabular}{llcl}
\hline Substances & Level of exposure & Cases $n$ & $O R^{\star}(95 \%$ CI) \\
\hline Fabric dust & insubstantial & 6 & $1 \cdot 4(0 \cdot 6-3 \cdot 6)$ \\
& substantial & 8 & $2 \cdot 6(1 \cdot 1-6 \cdot 0)$ \\
Wool fibres & any & 14 & $1 \cdot 9(1 \cdot 0-3 \cdot 7)$ \\
& insubstantial & 2 & $0 \cdot 8(0 \cdot 2-3 \cdot 6)$ \\
substantial & 5 & $2 \cdot 6(0 \cdot 9-7 \cdot 3)$ \\
Plastic dust & any & 7 & $1 \cdot 6(0 \cdot 7-3 \cdot 9)$ \\
& insubstantial & 4 & $1 \cdot 2(0 \cdot 4-3 \cdot 8)$ \\
Synthetic adhesives & substantial & 3 & $4 \cdot 4(1 \cdot 1-16 \cdot 9)$ \\
& any & 7 & $1 \cdot 8(0 \cdot 8-4 \cdot 4)$ \\
insubstantial & 13 & $1 \cdot 8(0 \cdot 9-3 \cdot 5)$ \\
Trichloroethylene & substantial & 7 & $1 \cdot 4(0 \cdot 6-3 \cdot 3)$ \\
& any & 20 & $1 \cdot 6(0 \cdot 9-2 \cdot 8)$ \\
insubstantial & 4 & $3 \cdot 8(1 \cdot 1-13 \cdot 6)$ \\
Some paints, varnishes & substantial & 4 & $3 \cdot 4(1 \cdot 0-12 \cdot 3)$ \\
& any & 8 & $3 \cdot 6(1 \cdot 5-9 \cdot 1)$ \\
& insubstantial & 14 & $3 \cdot 0(1 \cdot 5-6 \cdot 0)$ \\
& substantial & 2 & $0 \cdot 4(0 \cdot 1-1 \cdot 9)$ \\
& any & 16 & $1 \cdot 7(0 \cdot 9-3 \cdot 1)$ \\
\hline
\end{tabular}

«Based on logistic regression including age, years of schooling, and ethnic group. Control group consists of 1066 subjects, pooled from cancer and population controls.

†Paints used on surfaces other than metal and varnishes used on surfaces other than wood. decreased risk of melanoma was found for two substances (lubricating oils and greases, and $\mathrm{C}_{18+}$ alkanes).

Table 2 shows the industries and occupations for which at least one of the ORs from the multivariate analyses had a lower $95 \%$ CI greater than $0 \cdot 9$. Subjects who had spent 10 or more years working in industries manufacturing clothing, non-metallic mineral products, or electrical and electronic products had a significantly increased risk of melanoma. For each of these industries, the point estimate increased with increased time spent working in the industry. For occupations, subjects who had worked as a warehouse clerk or a salesman for 10 or more years were at increased risk of melanoma. Again there was some suggestion of a dose-response trend for these workers. Those who had worked for one to nine years as miners and quarrymen or chemical processing workers were also at increased risk of melanoma. There were very few workers who had worked in these two occupations for 10 or more years. As well as the occupations shown in table 1, there was a significant excess for clerks, but this was entirely due to the excess among the subset of warehouse clerks and is consequently not shown in the table.

Table 3 shows the substances for which at least one of the ORs from the multivariate analyses had a lower $95 \%$ CI greater than 0.9 . For fabric dust, wool fibres, and plastic dust, the point estimate of the OR was higher for subjects with substantial exposure compared with those with insubstantial exposure. We also found a significantly raised risk for substantial exposure to chlorinated alkenes, but all those cases exposed to chlorinated alkenes were also exposed to the more specific group of trichloroethylene so we have omitted the general group from the table.

\section{Discussion}

This study has several important advantages over other attempts to study the effect of occupation on melanoma. Because the study was community based rather than industry based we were able to obtain larger numbers of exposed cases than is usually possible; we were able to use incident cases rather than deaths; we had lifelong job histories; we were able to examine a wide range of substances, occupations, and industries; and we had access to information on several confounding factors. However, unlike most community based studies, we also had very detailed exposure assessment information: our method of assessment is acknowledged as the most accurate occupational exposure assessment available at present for community based studies. ${ }^{7}$ We also had access to both cancer and population control groups and showed that the estimates of risk of melanoma due to the different occupational circumstances differed little according to which control group was used. The resulting estimates with the pooled controls are less susceptible to any possible bias inherent in the choice of one or other of the control groups. 
We were able to obtain information on many but not all potential confounding factors. In particular, we had information on age, socioeconomic status, and ethnicity (which is correlated with complexion). We had no information on number of naevi, although it seems unlikely that this variable, independent of ethnicity, would be correlated so strongly with occupational exposures that it would confound the association between occupational exposure and melanoma. For exposure to the sun we had information on place of birth, and a residential history before the age of 15 , as there is some suggestion that the risk of melanoma is related to country of residence in childhood. ${ }^{8}$ However, we found that almost all of our subjects were born in Canada or northern Europe and had lived in these countries for the first 15 years of their lives. We were not able to collect detailed individual data on adult exposure to sun, and there may be some residual confounding after control for socioeconomic status if certain occupations, industries, or less probably, substances are associated with particular patterns of exposure to the sun.

We limited our analysis to those 118 occupational circumstances in which there were more than four exposed cases. Most of these did not seem to increase the risk of melanoma. This included several substances for which there were many exposed cases, such as petrol engine emissions (OR $1 \cdot 1,95 \%$ CI $0 \cdot 7-1 \cdot 8$ ), solvents (OR $0.8,95 \%$ CI $0.5-1 \cdot 3$ ), carbon monoxide (OR $1 \cdot 0$, 95\% CI $0 \cdot 6-1 \cdot 5$ ), and polycyclic aromatic hydrocarbons from petroleum (OR $0.9,95 \%$ CI $0 \cdot 6-1 \cdot 4$ ). In a bid to avoid the bias resulting from the publication of only so called positive results (those which are significant) we have listed the substances, occupations, and industries which did not significantly increase the risk of melanoma in the appendix of this paper. For many of the circumstances listed in the appendix, the statistical precision of our estimates was poor and consequently the lack of association is not well supported. For instance, one of the few occupations for which there have been some suspicions raised about a risk of melanoma is electrical power workers. However, many of the previous reports have had three or fewer incident cases or deaths and larger studies have failed to find any increase in risk. ${ }^{9-12}$ Our result was not significant but it cannot be considered as strong evidence against the hypothesis.

As may be expected in a study in which multiple comparisons were performed, there were two substances for which we found a significantly decreased risk of melanoma. Chance, or uncontrolled confounding seem more likely explanations for these findings than any true biologically protective effect.

The only published study similar to ours was a case-control study of 140 incident melanomas in the Netherlands. ${ }^{13}$ These investigators had information on potential confounders (including complexion, number of naevi, and exposure to the sun) and a history of each subject's occupations and industries. However, they had access only to self reports of exposure to substances and in their paper they did not systematically analyse risk in relation to these self reports. Nelemans et al ${ }^{13}$ reported several risk factors which we did not find or were not able to examine in our data. Among industries, they found a significantly increased risk of melanoma in the metal industry (OR 2.5, 95\% CI 1.1-5.6), whereas we found only a hint of an increased risk in the metal fabricating and machining industry (OR $1 \cdot 4,95 \%$ CI $0 \cdot 6-3 \cdot 2)$. They also found a risk of $1.9(95 \%$ CI $0.8-4.4)$ for workers in the transport and communication branch, whereas we found no increase in workers in air, motor, or railway transport, and could not examine communication workers.

For occupations, we found that miners and quarrymen had three to seven times the risk of incident melanoma, based on five exposed cases. A cohort study of gold and coal miners found an increased risk of mortality from melanoma but this was based on only three deaths and could easily have represented a chance finding. ${ }^{14}$ The associations we found between melanoma and services to business, and the occupations of warehouse clerk and salesman echo previous reports. ${ }^{15} 16$ These are very broad occupational groups and it is difficult to imagine exposure to substances which such a diverse group could have in common. There is some evidence that fluorescent lighting may be a risk factor for melanoma ${ }^{17}$ but we had no information on this exposure.

For industries, we found a significantly increased risk in the manufacture of electrical and electronic products (OR 2.4, 95\% CI 1.0-5.9), whereas the Dutch case-control study mentioned previously found a slight increase in risk in the electronics industry (OR $1 \cdot 5,95 \%$ CI $0 \cdot 5-4 \cdot 4) .{ }^{13}$ There has also been a report of a fourfold excess of deaths due to melanoma in workers who had been engaged in the manufacture of electrical capacitors (based on eight deaths) ${ }^{18}$ and a report of no increase in either incidence or mortality from melanoma in a cohort of semiconductor workers (based on three deaths and 13 incident cases). ${ }^{19}$ We found an increased risk for melanoma among workers involved in the manufacture of clothing (OR $4 \cdot 1,95 \%$ CI 1.7-9.8) but not among those working in the manufacture of textiles (OR $0.6,95 \%$ CI $0 \cdot 1-4 \cdot 9)$. The ORs were also raised in those exposed to fabric dust (OR $2 \cdot 6,95 \%$ CI 1.1-6.0), and wool fibres (OR 2.6, 95\% CI $0 \cdot 9-7 \cdot 3)$. The case-control study in the Netherlands ${ }^{13}$ found no association between work in the textile industry and melanoma (OR $1 \cdot 1,95 \%$ CI $0 \cdot 5-2 \cdot 4$ ). A study using cancer registry data ${ }^{20}$ found no increased proportional incidence ratio for melanoma among clothing workers in England and Wales (nine exposed cases), but a significant increase in the standardised registration ratio for this occupation in Sweden (22 exposed cases). A study of a cohort of synthetic textiles workers found no raised risk of melanoma (based on four deaths). ${ }^{21}$

For exposure to substances, we found an association between melanoma and exposure 
to plastic dust (seven exposed cases) but the $95 \%$ CIs for the ORs overlapped $1 \cdot 0$. A study using cancer registry data found an increased proportional cancer incidence ratio in workers from the rubber and plastic products industry but only among white workers. ${ }^{22}$ Our finding of an increased risk in workers exposed to trichloroethylene was not confirmed in studies of exposed cohorts of workers at an aircraft maintenance company, ${ }^{23}$ nor in several studies of dry cleaning workers. ${ }^{24-26}$ However, all these results were based on very small numbers of deaths or incident cases. The relations between melanoma and synthetic adhesives and between melanoma and our rather idiosyncratic grouping of "paints used on surfaces other than metal and varnishes used on substances other than wood" do not seem to have been examined previously.

Our case-control study on occupational circumstances and melanoma was based on pathologically confirmed diagnosis of cancer incidence, included detailed exposure assessment of hundreds of substances, and took account of potential confounding factors although some residual confounding may remain. Of the 118 occupational circumstances examined in this analysis, only two industries, three occupations, and four substances gave raised ORs which were significant at the $5 \%$ level. There is some previous evidence on occupations and industries as risk factors for melanoma, but there is hardly any scientific literature on substances. Except for the occupations of clerk and salesman, there is little supporting evidence in the scientific literature for any of the associations we found. Whereas the significant associations that we have shown may simply reflect the chance findings one would expect in a multiple testing context, it is prudent to consider these as worthwhile hypotheses to follow up or explore in other data sets.

There may well have been false negatives as well. The numbers of subjects exposed were low, the CIs wide, and we cannot exclude the possibility of small excess risks for many of the associations which failed to reach significance. Further, although considerable effort was devoted to the retrospective assessment of exposure, there was undoubtedly some misclassification of exposure which would have led to attenuation in the OR estimates. Finally, even if there are some occupational causes of melanoma among the substances we examined, it is possible that the levels of exposure experienced by subjects in this study were below those required to produce a detectable increase in risk. Thus, it cannot be concluded that the potential risk factors for melanoma that we have identified are the only ones in this population. If future studies are to provide any useful information on the relation between melanoma and occupational exposures, then it is essential that they include large numbers of cases and collect high quality data on exposures.

This study was funded by grants from the Institut de recherche en sécurité du travail du Québec, recherche en santé du Québec, the National Health Research and Development Program, and the National Cancer Institute of Canada. JS is a National Health Scholar. The fieldwork was supervised by Lesley Richardson and the chemical coding was carried out by Michel Gérin, Louise Nadon, Denis Bégin, and Ramzan Lakhani. Professor Ben Armstrong provided useful statistical advice

Appendix: Substances, industries, and occupations which were not associated with melanoma in any multivariate analyses (number of exposed cases in parentheses) ${ }^{\star}$

\section{Substances}

Abrasives dust (10), alkali, caustic solutions (6), $\mathrm{C}_{1}-\mathrm{C}_{4}$ alkanes (10), $C_{5}-C_{17}$ alkanes (22), $C_{18+}$ alkanes (18), aliphatic alcohols (9), aliphatic aldehydes (15), alumina (8), aluminium compounds (10), ammonia (8), amphibole asbestos (5), arc welding fumes (6), benzene (10), benzo(a)pyrene (10), biocides (5), calcium carbonate (5), calcium oxide (5), calcium oxide fumes (5), calcium sulphate (9), carbon monoxide (42), carbon tetrachloride (6), cellulose (6), chlorinated alkanes (8), chromium (vi) compounds (5), chromium compounds (11), cleaning agents (9), concrete dust (9), copper compounds (5), cotton dust (9), chrysotile asbestos (11), crystalline silica (16), diesel engine emissions (10), engine emissions (37), excavation dust (7), formaldehyde (11), gas welding fumes (7), hydrogen sulphide (5), hydrogen chloride (5), inks (5), inorganic acid solutions (12), inorganic insulation dust (10), inorganic pigments (5), iron compounds (14), iron fumes (5), iron oxides (5), lead compounds (37), leaded petrol (6), liquid fuel combustion products (6), lubricating oils and greases (17), metal oxide fumes (13), metallic dust (17), methane (6), methanol (5), mild steel dust (9), mineral spirits (6), mineral spirits used before 1970 (9), monoaromatic hydrocarbons (22), nickel compounds (6), nitrogen oxides (15), organic dyes and pigments (5), polyaromatic hydrocarbons (PAH) from any source (57), PAH from petroleum (54), PAH from sources other than coal, wood, or petroleum (14), polyester fibres (5), portland cement (5), pyrolysis fumes not classified elsewhere (11), soldering fumes (8), solvents (33), soot (6), stainless steel dust (5), sulphur dioxide (14), sulphuric acid (7), synthetic fibres (7), tin compounds (9), toluene (5), urea-formaldehyde (5), wood dust (11), zinc compounds (6).

\section{Industries}

Accommodation and food (5), air transport (6), chemical products (6), communications (5), construction (16), defence services (17), education (6), finance, insurance, and real estate (13), government (7), metal fabricating and machining (11), motor transport (8) railway transport (5), retail trade (12), services to business (19), textiles (5), transport equipment other than aircraft manufacture (5), wholesale trade (16).

\section{Occupations}

Administrators and managers (23), construction workers (8), electrical power workers (5), mechanics (5), motor transport workers (10), physical scientists (14), police, guards, and firemen (15), warehouse workers (6).

* Details of ORs (95\% CIs) are available upon request to the authors.

1 IARC Working Group on the Evaluation of Carcinogenic Risks to Humans Solar and ultraviolet radiation. Lyon: World Health Organization, 1992.

2 Beral V, Robinson N. The relationship of malignant melanoma, basal and squamous skin cancers to indoor melanoma, basal and squamous skin cancers to

3 Lee JAH, Strickland D. Malignant melanoma: social status and outdoor work. Br $f$ Cancer 1980;41:757-63.

4 Siemiatycki J, Risk factors for cancer in the workplace. CRC emiatycki J, Risk factors for can

5 Siemiatycki J, Wacholder S, Richardson L, Dewar R, Gérin $M$. Discovering carcinogens in the occupational environment: methods of data collection and analysis of a large ment: methods of data collection and analysis of a large Case-referent monitorin $1987 ; 13: 486-92$. 
6 Siemiatycki J, Dewar R, Nadon L, Gérin M. Occupational risk factors for bladder cancer: results from a case-control study in Montreal, Quebec, Canada. Am $\mathcal{F}$ Epidemio $1994 ; 140: 1061-80$.

7 Stewart PA, Stewart WF. Occupational case-control studies: II. Recommendations for exposure assessment. $A m \mathcal{F}$ Ind Med 1994;26:313-26.

8 Holman CJD, Armstrong BK. Cutaneous malignant melanoma and indicators of total accumulated exposure to the sun: an analysis separating histiogenetic types. $\mathcal{F}$ Natl Cancer Inst 1984;73:75-82.

9 Vågerö $D$, Olin $R$. Incidence of cancer in the electronics industry: using the new Swedish Cancer Environment Registry as a scre

10 Guenel P, Raskmark P, Andersen JB, Lynge E. Incidence of cancer in persons with occupational exposure to electromagnetic fields in Denmark. $\mathrm{Br} F$ Ind Med 1993; 50:758-64.

11 Theriault G, Goldberg $M$, Miller AB, Armstrong $B$, Guenel P, Deadman J, et al. Cancer risks associated with occupational exposure to magnetic fields among electric utility workers in Ontario and Quebec, Canada and

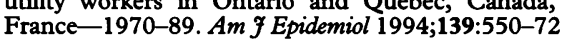

12 Armstrong B, Theriault G, Guenel P, Deadman J, Goldberg M, Heroux P. Association between exposure to pulsed electromagnetic fields and cancer in electric utility pulsed electromagnetic fields and cancer in electric utility workers in Quebec,

13 Nelemans PJ, Scholte R, Groenendal H, Kiemeney LALM, Rampen FHJ, Ruiter DJ, et al. Melanoma and occupation-results of a case-control study in the Netherlands. $B r \mathcal{F}$ Ind Med 1993;50:642-6.

14 Armstrong BK, McNulty JC, Levitt LJ, Williams KA, Hobbs MST. Mortality in gold and coal miners in western Australia with special reference to lung cancer. $B r F$ Ind Med 1979;36:199-205.

15 Spinelli J, Gallagher RP, Band PR, Threlfall WJ, Raynon D, Schellekens H. Occupational associations among
British Columbia male cancer patients. Can $f$ Public Health 1990;81:254-8.

16 Firth HM, Herbison GP, Cooke KR, Fraser J. Male cancer mortality by occupation-1973-86. N Z Med F 1993; 106:328-30.

17 Walter SD, Marrett LD, Shannon HS, From L, Hertzman C. The association of cutaneous malignant melanoma and fluorescent light exposure. Am F Epidemiol 1992; 135:749-62.

18 Mazzuckelli L, Schulte P. Notification of workers about an excess of malignant melanoma: a case study. $A m \mathcal{F}$ Ind Med 1993;23:85-91.

19 Sorahan T, Pope DJ, McKiernan MJ. Cancer incidence and cancer mortality in a cohort of semiconductor workand cancer mortality in a cohort of semicond

20 Vågerö D, Swerdlow AJ, Beral V. Occupation and malig nant melanoma: a study based on cancer registration data in England and Wales and in Sweden. $B r \mathcal{F}$ Ind Med 1990;47:317-24.

21 Goldberg MS, Theriault G. Retrospective cohort study of workers of a synthetic textiles plant in Quebec: I. Genera mortality. Am F Ind Med 1994;25:889-907.

22 Hall NEL, Rosenman KD. Cancer by industry: analysis of a population-based cancer registry with an emphasis on blue-collar workers. Am $₹$ Ind Med 1991;19:145-59.

23 Spirtas R, Stewart PA, Lee JS, Marano DE, Forbes CD, Grauman DJ, et al. Retrospective cohort mortality study of workers at an aircraft maintenance facility. I study of workers at an aircraft maintenance facility.
Epidemiological results. $\mathrm{Br} f$ Ind $\mathrm{Med}$ 1991;48: Epidemiol

24 Katz RM, Jowett D. Female laundry and dry cleaning workers in Wisconsin: a mortality analysis. Am $\mathcal{f}$ Public Health 1981;71:305-7.

25 Duh R-W, Asal NR. Mortality among laundry and dry cleaning workers in Oklahoma. Am $\mathcal{f}$ Public Health 1984;74:1278-80.

26 Blair A, Stewart PA, Tolbert PE, Gauman D, Moran FX, Vaught J, et al. Cancer and other causes of death among a cohort of dry cleaners. Br f Ind Med 1990;47:162-8.

\section{Vancouver style}

All manuscripts submitted to Occup Environ Med should conform to the uniform requirements for manuscripts submitted to biomedical journals (known as the Vancouver style.)

Occup Environ Med, together with many other international biomedical journals, has agreed to accept articles prepared in accordance with the Vancouver style. The style (described in full in the BMF, 24 February $1979, p$ 532) is intended to standardise requirements for authors.

References should be numbered consecutively in the order in which they are first mentioned in the text by Arabic numerals above the line on each occasion the reference is cited (Manson ${ }^{1}$ confirmed other reports $^{2-5}$. . .). In future references to papers submitted to Occup Environ Med should include: the names of all authors if there are seven or less or, if there are more, the first six followed by $e t$ al; the title of journal articles or book chapters; the titles of journals abbreviated according to the style of Index Medicus; and the first and final page numbers of the article or chapter. Titles not in Index Medicus should be given in full.

Examples of common forms of references are:

1 International Steering Committee of Medical Editors, Uniform requirements for manuscripts submitted to Uniform requirements for manuscripts submitt
biomedical journals. Br Med $¥$ 1979;1:532-5.

2 Soter NA, Wasserman SI, Austen KF. Cold urticaria: release into the circulation of histamine and eosinophil chemotactic factor of anaphylaxis during cold challenge. N Engl f Med 1976;294:687-90.

3 Weinstein L, Swartz MN. Pathogenic properties of invading micro-organisms. In: Sodeman WA Jr, Sodeman WA, eds. Pathologic physiology, mechanisms of disease. Philadelphia: W B Saunders, 1974:457-72. 